\title{
Glucose modulates recently reactivated memories
}

\author{
WARD A. RODRIGUEZ \\ University of California, Berkeley, California \\ and New Mexico Highlands University, Las Vegas, New Mexico \\ and
L. ROBERT VAN AUSDLE, KAREN DHANENS, and ADELA N. MONDRAGON New Mexico Highlands University, Las Vegas, New Mexico

\begin{abstract}
A passive avoidance to active avoidance negative transfer paradigm was used to investigate the effects of glucose on recently acquired and recently reactivated memories. Immediate post-passive avoidance training injections of glucose $(100 \mathrm{mg} / \mathrm{kg} \mathrm{s.c.})$ improved memory and thus interfered with the rats' ability to learn the one-way active avoidance task $24 \mathrm{~h}$ later. Rats receiving a memory reactivation treatment $24 \mathrm{~h}$ after passive avoidance training showed greater negative transfer to the active avoidance task presented $24 \mathrm{~h}$ later than did nonreactivated control animals. Furthermore, the administration of glucose $(32,100$, or $320 \mathrm{mg} / \mathrm{kg}$ ) following memory reactivation proactively interfered with the acquisition of the active avoidance; this effect followed an inverted U-shaped dose-response function. The ability of glucose $(100 \mathrm{mg} / \mathrm{kg})$ to alter the reactivated passive avoidance memory decreased as the interval between reactivation and glucose treatment was increased up to $30 \mathrm{~min}$. These results demonstrate that glucose modulates the processing of old memories that have been recently reactivated, just as it modulates the processing of new memories that have been recently acquired.
\end{abstract}

The administration of drugs and hormones after training influences subsequent performance (Martinez, Schulteis, \& Weinberger, 1991). One of the first hypotheses to account for this result suggests that drugs administered posttraining directly affect memory consolidation processes and thus lead to a stronger and more persistent neural representation of the training episode (McGaugh, 1966). However, studies showing that the effects of drugs and hormones depend not only on the strength and nature of the treatment (drug or hormone), but also on the strength of training (e.g., the unconditioned stimulus [US] intensity and the amount of training) and the treatment/training interaction, have led to a more modest hypothesis. According to this hypothesis, many drugs that enhance and impair memory do so by selectively promoting the processing of emotionally significant events, perhaps by mimicking the effects produced endogenously by naturally occurring substances (Gold \& McGaugh, 1975; Gold \& Zornetzer, 1983; Martinez et al., 1991; McGaugh, 1989). Drugs that operate in this way are called memory modulators (Gold, 1989; Schulteis \& Martinez, 1992).

This research was supported by a NIDA Supplement for Underrepresented Minorities in Biomedical and Behavioral Research and by NIGMS-MBRS GM-08066 to W.A.R., and by NIDA DA06192 to Joe L. Martinez, Jr. The authors express their gratitude to Oscar Domenech, David Phelps, and Arlene Horne for aid in conducting these experiments, and to Susan B. Rodriguez for helpful comments on this manuscript. Correspondence concerning this article should be addressed to W. A. Rodriguez, Department of Psychology, University of California, Berkeley, CA 94720.
Messier and White (1984) were the first to show that glucose administered posttraining could function as a cognitive enhancer. Subsequently, Gold (1986) showed that posttraining administration of glucose resulted in changes in performance characteristic of those produced by memory modulators, since the dose-response curve for the effect of glucose on conditioning was found to be $U$ shaped (maximally effective dose: $100 \mathrm{mg} / \mathrm{kg}$ ) and the ability of glucose to influence conditioned performance was found to be time dependent. Further evidence that glucose is an important memory modulator comes from studies showing that the maximally effective dose of glucose changes with US (footshock) intensity (Gold, Vogt, \& Hall, 1986), and that blood glucose levels after inhibitory avoidance training correlate with later performance (Hall \& Gold, 1986). Subsequently to these initial studies, the conditions under which glucose influences memory have been found to include not only aversive learning situations in animals (Messier \& White [1987], White \& Messier [1988], conditioned suppression; Gold [1986], single-trial inhibitory avoidance), but also appetitive learning situations in animals (e.g., Packard \& White [1990], radial arm maze; Messier \& Destrade [1988], operant response) and human cognitive processing (for a review, see Gold, 1991).

Gold (1991), Wenk (1989), and White (1991) all suggest that biologically significant events alter learning and memory via a common mechanism, and that an important component of this mechanism is the release of glucose from the liver and the subsequent effect of glucose on central neuromodulators. Glucose may be part of the 
reinforcement system that marks the importance of an event by changing the level or duration of active processing (cf. Martinez et al., 1991; White \& Milner, 1992) and thereby increasing associative strength (Wagner \& Brandon, 1989; Wickelgren, 1976). Gold (1991), Wenk (1989), and White (1991) argue that both appetitive and aversive stimuli normally cause the release of epinephrine from the adrenal medulla, which in turn causes the release of glucose into the blood from the liver. It is suggested that peripheral glucose affects the central nervous system either directly by active uptake into the brain (Gold, 1991; Wenk, 1989) or indirectly by hepatic detection of glucose levels that are relayed to the central nervous system by the celiac ganglion (White, 1991). These researchers all argue that central glucose selectively influences the neural systems involved in learning and memory. Glucose interacts both with central opioid peptide systems, which modulate (frequently impairing) learning and memory, and with central cholinergic systems, which modulate (frequently enhancing) learning and memory (Gallagher, 1984; Gold \& Zornetzer, 1983; McGaugh, 1989; Squire \& Davis, 1981; Stone, Cottrill, Walker, \& Gold, 1988; Stone, Walser, Gold, \& Gold, 1991). Because glucose attenuates the actions of opioidergic mechanisms and augments the actions of cholinergic mechanisms, Wenk (1989) terms glucose a "cognitive enhancer."

Important to the study of memory processing is the finding that re-presenting some features of the training episode following conditioning and before testing affects subsequent performance of a large number of tasks, under a variety of prompting or prior-cuing conditions (Spear, 1976, 1981; Spear, Miller, \& Jagielo, 1990). Effective retrieval cues are believed to recreate in active memory many of the conditions that existed at the time of acquisition; the resulting enhancement in performance is consistent with Tulving's encoding specificity hypothesis (Tulving \& Thompson, 1973). Following training with an aversive US, an especially effective reactivation treatment is the reintroduction of the US in the presence of original learning contextual cues (Rescorla \& Heth, 1975; Richardson, Riccio, \& Mowrey, 1982; Spear, Hamberg, $\&$ Bryan, 1980). New memories recently acquired and old memories previously acquired but recently reactivated or retrieved share many functional similarities (Gordon, 1981; Riccio \& Ebner, 1981; Spear, 1976, 1981; Spear $\&$ Mueller, 1984). It has been suggested that just like recently acquired memories, recently reactivated memories are in a labile state and thus highly susceptible to modification (Gordon, 1981; Lewis, 1979; Miller \& Marlin, 1984; Miller \& Springer, 1973; Spear, 1976, 1981). That is, the decoding and subsequent retrieval of a memory trace constitutes an opportunity for its modification. Memory reactivation treatments are believed to affect subsequent performance either by stabilizing the retrieval route or by updating and reconstructing the original memory (Izquierdo, 1989; Miller \& Marlin, 1984; Sara, 1991; Spear \& Mueller, 1984; Wickelgren, 1976).
Drugs and hormones affect not only memory storage; they also affect memory retrieval (Quartermain, 1983; Riccio \& Ebner, 1981; Rodriguez, Phillips, Rodriguez, \& Martinez, in press; Sara, 1991). Preretention testing injections of catecholamines (Quartermain, 1983; Sara, 1985) attenuate forgetting. Recently, Stone, Rudd, and Gold (1990) showed that glucose produces a dose-dependent attenuation of forgetting of an inhibitory avoidance response when it is administered $30 \mathrm{~min}$ prior to the retention test. However, when drugs and hormones are administered shortly before testing they may influence not only memory retrieval but also sensory, motor, and motivational task-relevant factors. Further, long-term effects on performance cannot be assessed when the drug-test interval is short.

The present study was designed to extend the findings of Gold (1991) and White (1991) that demonstrate that glucose is an important memory modulator by investigating the effects of glucose on recently acquired and recently reactivated memories. Importantly, we selected an experimental approach for these studies that permitted assessment of glucose's memorial effects independently of any possible effects on nonassociative memorial variables. For these studies, we conducted passive avoidance training and $24 \mathrm{~h}$ later we reactivated the rats' memory with a noncontingent footshock delivered in the experimental context. We administered glucose after the reactivation treatment and tested the rats $24 \mathrm{~h}$ later on a reversal (active avoidance) task. This approach not only reduced the likelihood that glucose was affecting nonassociative memorial variables, but, by testing the rats $24 \mathrm{~h}$ after the reactivation treatment, we were able to measure persistent drug effects on recently reactivated memories and retrieval mechanisms (Gordon, 1977; Gordon \& Spear, 1973).

The purpose of Experiment 1 was to extend to a new experimental paradigm, passive to active avoidance negative transfer, the finding that administration of glucose $(100 \mathrm{mg} / \mathrm{kg})$ modulates recently acquired memories. Experiment 2 was designed to demonstrate the presence of a reactivation effect and to enable the investigation of its dose-dependent modulation by glucose. In Experiment 3, we investigated the time period during which old memories, once reactivated, remain vulnerable to modification by glucose administration.

\section{EXPERIMENT 1 \\ Effects of Glucose on Recently Acquired Memories}

\section{Method}

Subjects. The subjects were 48 experimentally naive male SpragueDawley rats, approximately 100 days of age at the beginning of training. They were housed individually in a temperature-controlled room and were maintained on a 12:12-h light:dark cycle $(0700 \mathrm{~h}$ on). Food and water were available ad lib. Behavioral testing was performed between 1200 and $1600 \mathrm{~h}$. All animal use and testing procedures were approved in advance by the Animal Care and Use Committee at New Mexico Highlands University. 
Apparatus. A single avoidance apparatus, similar to that described by Spear et al. (1980), was used for both passive and active avoidance conditioning. It consisted of adjacent white and black Plexiglas chambers of identical dimensions $(27 \times 14.5 \times 14 \mathrm{~cm})$. The chambers were separated by a guillotine door that could be lowered to a height of $2.5 \mathrm{~cm}$. The grid floor of both chambers consisted of stainless steel bars $6 \mathrm{~mm}$ in diameter and spaced $1.7 \mathrm{~cm}$ between centers. A scrambled footshock $(0.5 \mathrm{~mA})$ could be delivered to either chamber by a Lafayette shock generator (82404/5.SS). A $2-\mathrm{Hz}$ flashing light $(7.5 \mathrm{~W})$ was mounted on the outside of the end wall of the white chamber. Lowering the guillotine door activated the flashing light and a timer, both of which were deactivated when the rat crossed a photobeam located in the middle of the dimly illuminated black chamber. A wire mesh cage $(25 \times 20 \times 18 \mathrm{~cm})$ was used both to transport subjects and to hold them during the intertrial intervals. Constant background noise $(63 \mathrm{~dB})$ was provided by a white noise generator. Stimulus presentation and response recording were programmed with computer and solid-state modules.

Design and drugs. The subjects were assigned randomly to either a saline or a glucose treatment group. Glucose $(100 \mathrm{mg} / \mathrm{kg})$ was prepared in saline. Injections were delivered subcutaneously in the back of the neck, 1 to $2 \mathrm{~cm}$ posterior to the base of the skull. All injections were blind coded.

Procedure. At the start of each passive avoidance training trial, the rat was placed in the white chamber, facing the black chamber. After $3 \mathrm{sec}$, the guillotine door opened, which started a 60 -sec clock and the flashing light. If the rat crossed into the black chamber within $60 \mathrm{sec}$, the guillotine door closed and the rat received a mild footshock $(0.5 \mathrm{~mA}, 1 \mathrm{sec})$. Crossing to the black chamber was scored as an incorrect response. If the rat remained in the white chamber for $60 \mathrm{sec}$, a correct (passive) avoidance response was recorded. After making a correct or incorrect response, the rat was placed in the holding cage for a 30-sec intertrial interval. All subjects were trained to a criterion of five consecutive correct responses. Immediately after reaching criterion, the rat was removed from the apparatus and given a glucose or saline injection. It was then returned to its home cage in the colony room for the retention interval.

Active avoidance training occurred $24 \mathrm{~h}$ later. At the start of each active avoidance training trial, the rat was placed in the white chamber, facing the black chamber; $3 \mathrm{sec}$ later, the guillotine door opened, and the flashing light and a 5-sec timer were started. If the rat did not cross into the black chamber within $5 \mathrm{sec}$, a 0.5 -mA footshock was activated; it continued until the rat entered the black chamber. This was scored as an incorrect response. A correct response was recorded if the rat entered the black chamber before $5 \mathrm{sec}$ had elapsed (i.e., before the footshock was activated). The subject remained in the black chamber for $10 \mathrm{sec}$ and then was placed into the holding cage for the 30 -sec intertrial interval. All rats were trained to a criterion of five consecutive (active) avoidances (30-trial maximum). Animals not reaching criterion were assigned a score of 30 .

Data analysis. The number of trials to passive and active avoidance criterion was analyzed by means of analyses of variance (ANOVA). All a priori hypotheses were evaluated by standard methods described by Keppel (1991). Correspondence between the data and the general linear model assumptions was confirmed by exploratory ANOVA techniques described by Hoaglin, Mosteller, and Tukey (1991). For all statistical tests, the rejection criterion was $p<.05$.

\section{Results and Discussion}

The glucose and saline treatment groups did not differ significantly on the mean number of trials to reach criterion on the passive avoidance task $[M=7.52 ; F(1,46)<$ $1.0]$, indicating that both groups of animals acquired the initial passive avoidance response at similar rates.
Figure 1 shows that rats receiving an immediate postpassive avoidance training injection of glucose $(100 \mathrm{mg} / \mathrm{kg})$ took significantly more trials to reach criterion on the active avoidance task than did saline-injected control rats $[F(1,46)=22.37, p<.001]$, indicating that glucose produces greater proactive interference than does saline administration with the negative transfer active avoidance test. These results are consistent with those of many other studies, in demonstrating that a posttraining injection of glucose $(100 \mathrm{mg} / \mathrm{kg})$ improves the retention of a recently acquired response (Gold, 1986; Hall \& Gold, 1986; White, 1991).

\section{EXPERIMENT 2}

\section{Dose-Response Function for the Effect of Glucose on Recently Reactivated Memories}

\section{Method}

Subjects and Apparatus. The subjects were 77 male SpragueDawley rats, 75 days of age at the start of the experiment. The housing and maintenance conditions were the same as in Experiment 1. The avoidance apparatus was identical to that described in Experiment 1, although Experiments 1 and 2 were conducted in different experimental rooms. A clear Plexiglas chamber $(28 \times 21 \times 20 \mathrm{~cm})$ with a grid floor identical to that in the avoidance apparatus served as the reactivation chamber.

Procedure. In order to avoid response ceiling effects, all subjects in this experiment were trained to a criterion of three con-

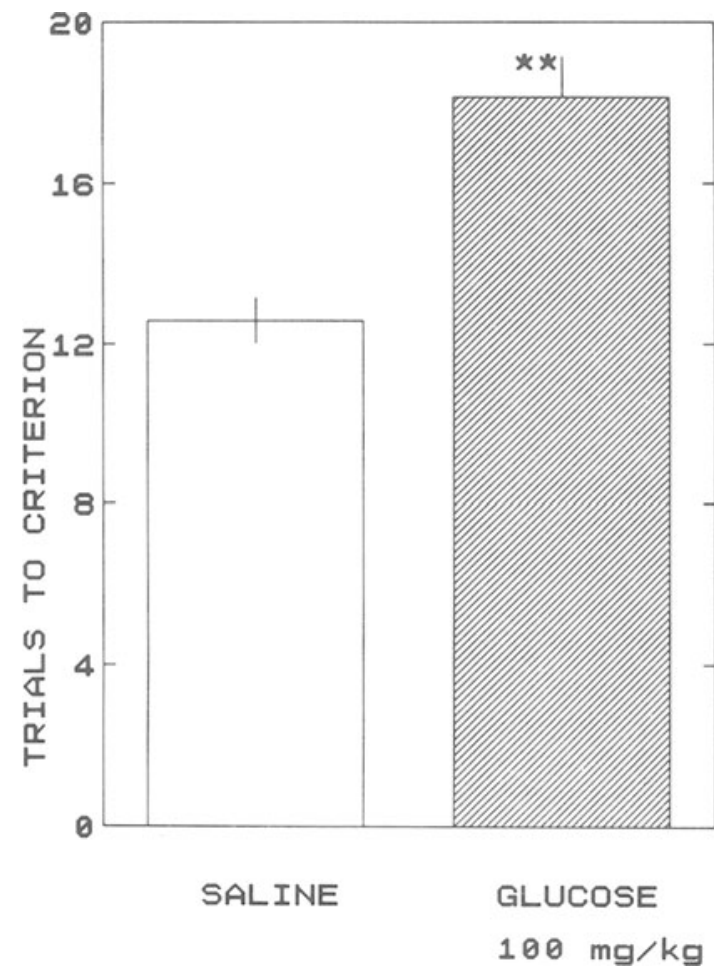

Figure 1. The effect of glucose $(100 \mathrm{mg} / \mathrm{kg} \mathrm{s.c.)}$ administered immediately after reactivation treatment on one-way active avoidance performance 24 h later. Animals treated with glucose $(n=24)$ took significantly more trials to reach criterion on the negative transfer task than did saline-treated $(n=24)$ control animals $(* * p<.001)$. 
secutive passive avoidance responses. In all other respects, passive and active avoidance training followed the procedures used in Experiment 1 . Twenty-four hours after passive avoidance training, the rat was returned to the experimental room for the reactivation treatment. Once in the experimental room, the rat was removed from its holding cage, placed into the clear Plexiglas reactivation chamber, and $3 \mathrm{sec}$ later given a mild footshock $(0.5 \mathrm{~mA}, 1 \mathrm{sec})$. After $10 \mathrm{sec}$, the subject was removed from the reactivation chamber, given an injection of glucose $(32,100$, or $320 \mathrm{mg} / \mathrm{kg})$ or saline, and then returned to its home cage in the colony room. A separate control group of animals received neither the reactivation treatment nor an injection. Twenty-four hours later, all animals were trained on the active avoidance task. Assignment to the five treatment groups was random.

\section{Results and Discussion}

Rats in the five treatment groups did not differ significantly on the number of trials required to reach criterion on the passive avoidance task $[M=4.65 ; F(4,72)=1.04$, $p=.39$ ]. Thus, as in Experiment 1, the subjects in each group learned the passive avoidance response at the same rate.

Figure 2 depicts the number of trials required for each group to reach criterion during active avoidance training. The omnibus one-way ANOVA was significant $[F(4,72)$ $=11.03, p<.0001]$; planned comparisons revealed that

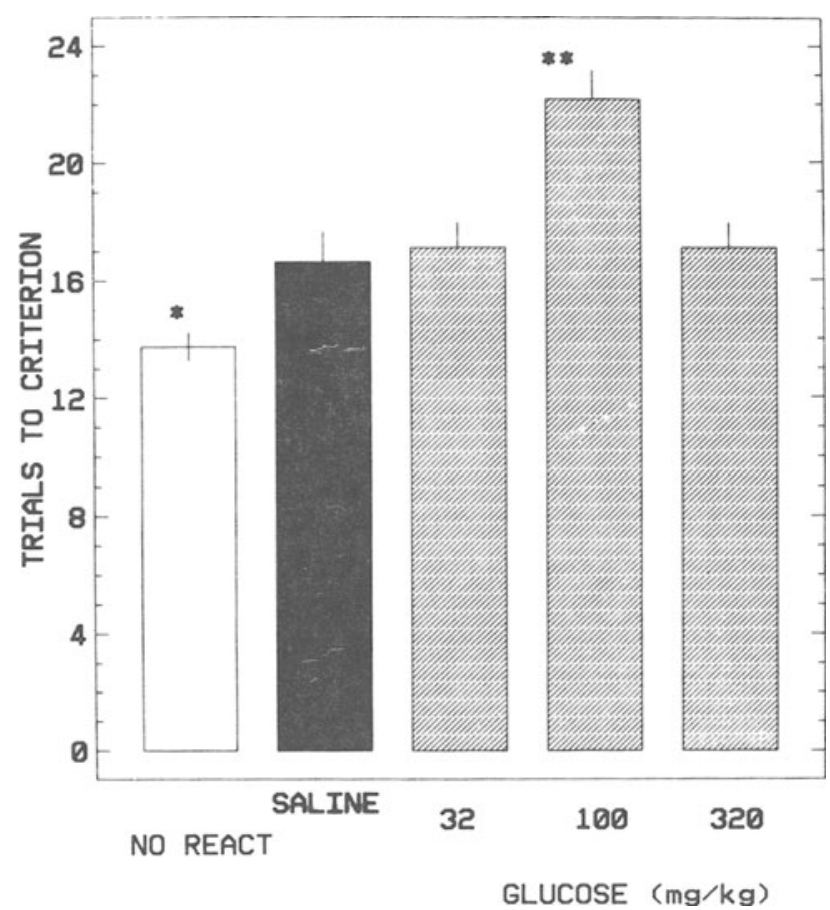

Figure 2. Effects of reactivation treatment, and of glucose administered immediately after reactivation treatment, on one-way active avoidance performance $24 \mathrm{~h}$ later. Rats that did not receive reactivation treatment (no react, $n=14$ ) took significantly fewer trials $\left({ }^{*} p<.05\right)$ to reach criterion than did animals receiving reactivation treatment and saline $(n=13)$. When compared with saline, glucose at a dose of $100 \mathrm{mg} / \mathrm{kg} \mathrm{sc}\left(n=14 ;{ }^{* *} p<.01\right)$ but not at a lower $(32 \mathrm{mg} / \mathrm{kg} ; n=18)$ or a higher $(320 \mathrm{mg} / \mathrm{kg} ; n=18)$ dose, produced significant negative transfer. the subjects that did not receive the reactivation treatment acquired the active avoidance response faster than did the postreactivation, saline-injected control animals $[F(1,72)$ $=4.85, p<.03]$. This finding demonstrates increased retention of passive avoidance training when it is followed $24 \mathrm{~h}$ later by a reactivation treatment, since the reactivation treatment produced greater negative transfer on the reversal (active avoidance) task. This result is consistent with the findings of Spear et al. (1980), who report that reintroducing rats to the conditioning context and the US (shock) affects the memory of the original training episode.

Figure 2 also shows that glucose produces a dosedependent enhancement of recently reactivated memories. Planned comparisons between the reactivation saline control treatment and each glucose dose revealed the presence of a U-shaped dose-response function, since a glucose dose of $100 \mathrm{mg} / \mathrm{kg}[F(1,72)=17.60, p=.0001]$, but not of $32 \mathrm{mg} / \mathrm{kg}[F(1,72)=0.16, p=.69]$ or $320 \mathrm{mg} / \mathrm{kg}$ $[F(1,72)=0.13, p=.72]$, given after the reactivation treatment, increased significantly the number of trials required to reach criterion on the negative transfer (active avoidance) task. Further corroborating the presence of a U-shaped dose-response function for the effects of postreactivation glucose treatment was a significant quadratic component for the glucose effect $[F(1,47)=$ $5.29, p=.026]$.

Together, these results indicate that the reactivation treatment increased the retention of the passive avoidance response and thus led to proactive interference during the acquisition of the reversed (active avoidance) response. The results also indicate that glucose enhances the retention of a recently reactivated memory, and that this effect is dose dependent and follows a U-shaped function.

\section{EXPERIMENT 3 \\ Time Dependency of the Effect of Glucose on Recently Reactivated Memories}

\section{Method}

Subjects and Apparatus. The subjects were 160 male SpragueDawley rats, 75 days of age at the start of the experiment. The apparatus, housing, and maintenance conditions were the same as in Experiment 2.

Procedure. The passive avoidance training, reactivation treatment, and active avoidance training procedures were identical to those used in Experiment 2. However, in this experiment, glucose (100 $\mathrm{mg} / \mathrm{kg}$ ) or saline was administered either immediately 2,5 , or $30 \mathrm{~min}$ after the reactivation treatment. The subjects were assigned randomly to the eight treatment conditions.

\section{Results and Discussion}

A one-way ANOVA of the trials to criterion on the passive avoidance task showed that rats in the eight treatment groups did not differ significantly $[M=4.2$; $F(7,152)=1.09, p=.37$ ]. Figure 3 presents the mean number of trials to criterion for the glucose- and salinetreated animals at each of the four reactivation-injection intervals. Planned comparisons between the glucose and saline treatments at each reactivation-injection interval showed that at both the immediate $[F(1,152)=6.18, p=$ 


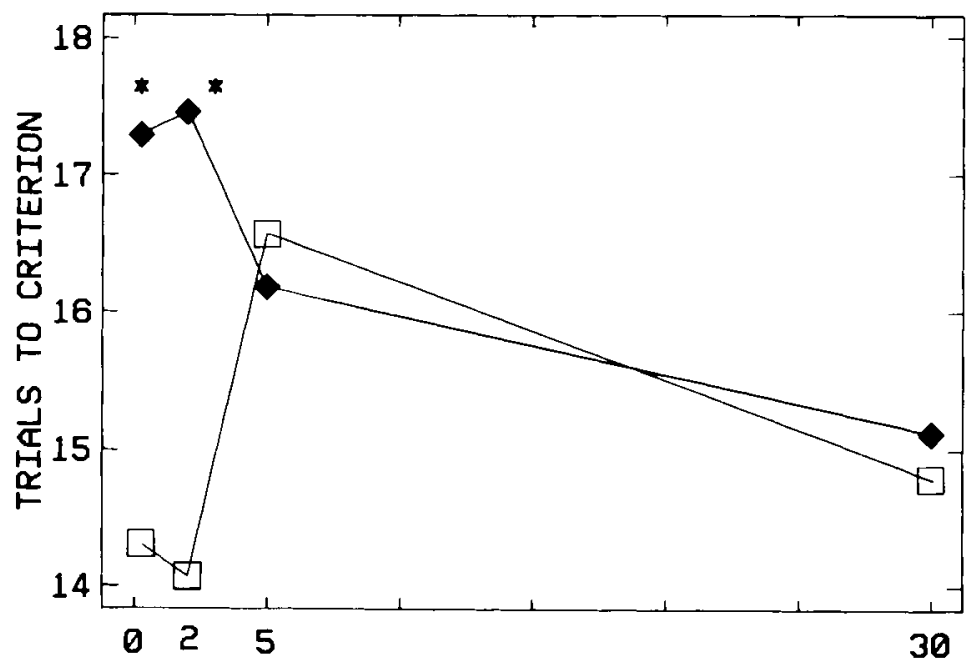

REACTIVATION INJECTION INTERVAL (min)

\begin{abstract}
Figure 3. Time dependency of the effect of glucose $(100 \mathrm{mg} / \mathrm{kg} \mathrm{s.c.})$ on reactivated memories. When compared with saline (open squares) treatment ( $n=16$, immediate; $n=13,2 \mathrm{~min} ; n=23,5 \mathrm{~min} ; n=24,30 \mathrm{~min}$ ), administration of glucose (filled diamonds) immediately $(n=17)$ or 2 min $(n=13)$ after reactivation, but not $5 \mathrm{~min}(n=28)$ or $30 \mathrm{~min}(n=26)$ after reactivation, resulted in significantly more trials $\left({ }^{*} p<.05\right)$ to reach criterion on the negative transfer oneway avoidance task presented $24 \mathrm{~h}$ later.
\end{abstract}

$.01]$ and the $2-\min [F(1,152)=6.28, p=.01]$, but not the 5 -min $[F(1,152)=0.16, p=.69]$ or the 30 -min $[F(1,152)=0.11, p=.74]$ intervals, glucose-treated subjects required more trials to reach criterion on the active avoidance task than did the corresponding saline-treated subjects.

An orthogonal polynomial analysis of trend across the reactivation-injection intervals was conducted separately for the glucose- and saline-treated subjects. This analysis indicated that the effects of postreactivation glucose injections at varying time intervals were linear $[F(1,80)$ $=5.03, p=.03$, accounting for $92.8 \%$ of the interval variance], whereas the effects of postreactivation saline treatment at varying time intervals followed a more complex quadratic trend $[F(1,72)=5.48, p=.02$, accounting for $76.4 \%$ of the interval variance]. These results indicate that it is only when glucose $(100 \mathrm{mg} / \mathrm{kg})$ is administered shortly after the context-shock reactivation treatment that differences in the subsequent acquisition of the active avoidance response are evident. Thus the data in Experiment 3 replicate (immediate treatment) and extend (2-min reactivation-injection interval) the conditions under which postreactivation glucose injections will proactively affect the subsequent acquisition of a reversal task. The results suggest further that, within our experimental paradigm, the effects of glucose on recently reactivated memories are linearly time dependent across the 30-min postreactivation interval. The quadratic nature of the effect of postreactivation saline treatment at varying time intervals is somewhat more difficult to explain. The unexpected interference observed at the 5-min reactivationsaline injection interval was replicated three times. Because so little is known about the way in which the conditions of reactivation interact (Spear et al., 1990), it is possible that the shape of this function may be specific to situations in which the US (footshock) is a component of the reactivation treatment.

\section{GENERAL DISCUSSION}

It has been found in previous studies that glucose modulates recently acquired appetitively and aversively motivated memories (see Gold, 1991, and White, 1991, for reviews). The present data provide additional evidence that glucose $(100 \mathrm{mg} / \mathrm{kg})$ enhances newly acquired aversively motivated memories. However, this study is the first demonstration that glucose can enhance memory in a passive avoidance to active avoidance negative transfer design. Our results also are consistent with prior findings that a context-footshock reactivation treatment can attenuate forgetting (Richardson et al., 1982; Spear et al., 1980). Most importantly, our results suggest that glucose modulates recently reactivated memories, and that just as with recently acquired memories (Gold, 1986), the modulation by glucose of recently reactivated memories follows a U-shaped dose-response function. We also demonstrated that the modulation by glucose $(100 \mathrm{mg} / \mathrm{kg})$ of a reactivated, 24-h-old, passive avoidance memory de- 
creases monotonically as the interval between reactivation and glucose administration increases. Because we found the effects of glucose on reactivated memories to be time dependent, it is unlikely that the effects of glucose administered immediately after reactivation are due to nonspecific negative transfer. Thus our results suggest that glucose, when administered after reactivation, acts as a memory modulator (Gold, 1989; Gold \& Zornetzer, 1983; Schulteis \& Martinez, 1992), because the dose-response function for this effect is $U$ shaped, and because the effect is time dependent.

Only one other study in animals demonstrated that glucose affects the processing of old memories (Stone et al., 1990). However, in that study, glucose was administered 30 min prior to testing, and there was no independent verification that the glucose was acting on a reactivated memory. The present study showed in three ways that glucose can modulate reactivated memories. First, because we tested the animals $24 \mathrm{~h}$ after glucose administration, and because glucose injections produce only a short-lived elevation of plasma glucose levels (Hall \& Gold, 1986), alterations by glucose administration of nonmemorial performance factors can be assumed to be absent during testing. Second, because the interval between glucose administration and testing in our study was $24 \mathrm{~h}$, we were able to demonstrate long-term or persistent effects of glucose on reactivated memories. To our knowledge, this is the first study describing the dose-response function for the long-term effects of a drug on a reactivated memory. Third, in this study, we have reported both a primary context-footshock reactivation effect and its susceptibility to modulation by glucose. This is noteworthy because none of our glucose doses themselves interfered with the primary reactivation effect; that is, in no case did glucoseinjected animals perform like nonreactivated rats. Thus our results are consistent with the prior findings that, when compared with saline injections, glucose does not interfere with learning and memory (Gold [1986], 1.0-500 $\mathrm{mg} / \mathrm{kg}$ glucose; White [1991], $0.1-4 \mathrm{~g} / \mathrm{kg}$ glucose), and with the suggestion that glucose may be a cognitive enhancer (Wenk, 1989).

In the present study, we reintroduced the US (footshock) within the context of the original learning episode. When compared with nonreactivated control animals, rats receiving the reactivation treatment took longer to acquire the active avoidance response measured $24 \mathrm{~h}$ later. This suggests that the context-US reactivation treatment affected the rats' memory for the original training episode. It has been suggested that reactivation treatments modify, and lead to the reorganization of, the original memory (Gordon, 1981; Izquierdo, 1989; Miller \& Marlin, 1984; Sara, 1991; Spear, 1976, 1981; Spear \& Mueller, 1984). In accord with this view, in the present experiment, the memory reactivation treatment resulted in retrieval-based consolidation and a more complex and cohesive memory for the passive avoidance episode. This more distinctive memory is presumably accessed more easily, and thus it interferes with the subsequent acquisition of the active avoidance task. There is extensive evidence that memory is influenced by activation of brain systems involved in arousal (e.g., Gold, 1991; Koob, 1991; Martinez et al., 1991; McGaugh, 1989; White \& Milner, 1992). In the present study, the US (footshock) served as part of the reactivation treatment, and thus it is possible that the value of the US, perhaps through context-US conditioning (Bouton \& Bolles, 1979), was thereby modified. Alternatively, Spear and Mueller (1984) argue that with each reactivation episode, the efficiency of the retrieval circuit itself may be enhanced. Thus both the nature of the stored representation and its accessibility may change as a result of a reactivation episode.

Our observed dose-response function for the effects of glucose on reactivated memories was $U$ shaped. Previous studies demonstrated that the dose-response functions for the effects of posttraining (Gold, 1986) and pretesting (Stone et al., 1990) glucose on subsequent performance also have an inverted $U$ shape. Together with our findings, these results indicate that glucose affects not only the acquisition of new memories, but also the further processing (retrieval and/or retrieval-based consolidation) of old memories, in accordance with an inverted U-shaped function. Furthermore, because the effects of glucose on new and old memories share a number of functional similarities (U-shaped dose-response function, time dependency), they also may share common biological substrates (cf. Gold, 1991; Wenk, 1989; White, 1991).

The presence of an inverted U-shaped function is interpreted by many researchers (e.g., Gold, 1991; Koob, 1991; McGaugh, 1989; Martinez et al., 1991) to indicate that there is an optimal level of drug for modulating learning and memory. Either too little or too much drug will fail to induce brain states optimal for memory processing and hence will not lead to the development of a distinctive memory. Interestingly, an inverted U-shaped relationship is also observed between learning and the interval between the conditioned stimulus (CS) and the US. The latter function is explained by behavioral theories of associative learning (see, e.g., Wagner \& Brandon, 1989) as being the result of conjoint rehearsal of the CS and US traces in active or working memory, and this coprocessing is thought to be optimized at certain CS-US intervals. If drugs modulate CS and/or US processing, perhaps a common mechanism can account for both the U-shaped nature of the dose-response function for drug effects on learning and the U-shaped relationship between learning and the CS-US interval.

Gold (1991) and Wenk (1989) suggest that as a result of increasing central cholinergic and decreasing central opioidergic activity, glucose administration can mark the salience or importance of an episode or event. Recent evidence for glucose facilitation of hippocampal cholinergic activity (Durkin, 1989), especially under conditions of high acetylcholine demand (Messier, Durkin, Mrabet, \& Destrade, 1991), may be important to the interpretation of our results for two reasons. First, the hippocampus is hypothesized to have an important role in the processing 
of contextual information (e.g., Hirsh, 1980; Kim \& Fanselow, 1992; Selden, Everitt, Jarrard, \& Robbins, 1991; Teyler \& DiScenna, 1986; Winocur \& Gilbert, 1984; Winocur, Rawlins, \& Gray, 1987), and we used the learning context as a retrieval cue. Second, the hippocampus is posited to be the site for retrieval cue-engram interaction and modification (Moscovitch \& Umiltà, 1991; Teyler \& DiScenna, 1986), and we believe that the study of reactivated memories and of their modification by drugs and lesions can elucidate the site(s) at which retrieval cues are brought into interaction with stored representations. Thus studies such as ours may lead to an understanding of the mechanism(s) common to the effects of glucose on recently acquired and recently reactivated memories, as well as help to uncover the mechanism(s) underlying memory storage and retrieval.

\section{REFERENCES}

Bouton, M. E., Bolles, R. C. (1979). Role of conditioned contexuual stimuli in reinstatement of extinguished fear. Joumal of Experimental Psychology: Animal Behavior Processes, 5, 368-378.

DURKIN, T. (1989). Central cholinergic pathways and learning and memory processes: Presynaptic aspects. Comparative Biochemistry \& Physiology, 93A, 273-280.

GAllaGHER, M. (1984). Neurochemical modulation of memory: A case for opioid peptides. In L. Squire \& N. Butters (Eds.), The neuropsychology of memory (pp. 579-587). New York: Guilford.

GoLD, P. E. (1986). Glucose modulation of memory storage processing. Behavioral \& Neural Biology, 45, 342-349.

Goin, P. E. (1989). Neurobiological features common to memory modulation by many treatments. Animal Leaming \& Behavior, 17, 94-100.

GoLD, P. E. (1991). An integrated memory regulation system: From blood to brain. In R. C. A. Frederickson, J. L. McGaugh, \& D. L. Felten (Eds.), Peripheral signaling of the brain: Role in neural-immune interactions and learning and memory (pp. 391-419). Toronto: Hogrefe \& Huber.

Gold, P. E., MCGAugh, J. L. (1975). A single-trace, two process view of memory storage processes. In D. Deutsch \& J. A. Deutsch (Eds.), Short-term memory (pp. 355-390). New York: Academic Press.

Gold, P. E., VoGt, J., \& HALl, J. L. (1986). Glucose effects on memory: Behavioral and pharmacological characteristics. Behavioral \& Neural Biology, 46, 145-155.

Gold, P. E., \& ZoRNetzer, S. F. (1983). The mnemon and its juices: Neuromodulation of memory processes. Behavioral \& Neural Biology, 38, 151-189.

GoRDON, W. C. (1977). Susceptibility of a reactivated memory to the effects of strychnine: A time-dependent phenomenon. Physiology \& Behavior, 18, 95-99.

GoRDON, W. C. (1981). Mechanisms of cue-induced retention enhancement. In N. E. Spear \& R. R. Miller (Eds.), Information processing in animals: Memory mechanisms (pp. 319-339). Hillsdale, NJ: Erlbaum.

GoRDON, W. C., \& SPEAR, N. E. (1973). The effects of strychnine on recently acquired and reactivated passive avoidance memories. Physiology \& Behavior, 10, 1071-1075.

HALL, J. L., \&oLD, P. E. (1986). The effects of footshock, epinephrine, and glucose injections on plasma glucose levels in rats. Behavioral \& Neural Biology, 38, 151-189.

HiRsH, R. (1980). The hippocampus, conditional operations, and cognition. Physiological Psychology, 8, 175-182.

Honglin, D. C., Mosteller, F., TUkey, J. W. (1991). Fundamentals of exploratory analysis of variance. New York: Wiley.

IzQUIERDO, I. (1989). Different forms of post-training memory processing. Behavioral \& Neural Biology, 51, 171-202.
KEPPEL, G. (1991). Design and analysis: A researcher's handbook (3rd ed.). Englewood Cliffs, NJ: Prentice-Hall.

KIM, J. J., \& FANSELow, M. S. (1992). Modality-specific retrograde amnesia of fear. Science, 256, 675-676.

KоOB, G. F. (1991). Arousal, stress, and inverted U-shaped curves: Implications for cognitive function. In R. G. Lister \& H. J. Weingartner (Eds.), Perspectives on cognitive neuroscience (pp. 300-313). New York: Oxford University Press.

LEWIS, D. J. (1979). Psychobiology of active and inactive memory. Psychological Bulletin, 86, 1054-1083.

Martinez, J. L., JR., Schulteis, G., Weinberger, S. B. (1991). How to increase and decrease the strength of memory traces: The effects of drugs and hormones. In J. L. Martinez \& R. P. Kesner (Eds.), Learning and memory: A biological view (2nd ed., pp. 149-198). New York: Academic Press.

MCGAugh, J. L. (1966). Time-dependent processes in memory storage. Science, 153, 1351-1358.

MCGAUGH, J. L. (1989). Involvement of hormonal and neuromodulatory systems in the regulation of memory storage. Annual Review of Neuroscience, 12, 255-287.

Messier, C., \& Destrade, C. (1988). Improvement of memory for an operant response by post-training glucose in mice. Behavioral Brain Research, 31, 185-191.

Messier, C., Durkin, T., Mrabet, O., \& Destrade, C. (1991). Contribution of hippocampal acetylcholine synthesis to the memoryimproving action of glucose. In R. C. A. Frederickson, J. L. McGaugh, \& D. L. Felten (Eds.), Peripheral signaling of the brain: Role in neural-immune interactions and leaming and memory (pp. 473477). Toronto: Hogrefe \& Huber.

Messier, C., White, N. M. (1984). Contingent and non-contingent actions of sucrose and saccharin reinforcers: Effects on taste preference and memory. Physiology \& Behavior, 32, 195-203.

Messier, C., \& White, N. M. (1987). Memory improvement by glucose, fructose, and two glucose analogs: A possible effect on peripheral glucose transport. Behavioral \& Neural Biology, 48, 104-127.

Miller, R. R., MARLiN, N. A. (1984). The physiology and semantics of consolidation. In H. Weingartner \& E. S. Parker (Eds.), Memory consolidation: Psychobiology of cognition (pp. 85-110). Hillsdale, NJ: Erlbaum.

Miller, R. R., \& Springer, A. D. (1973). Amnesia, consolidation and retrieval. Psychological Review, 80, 69-79.

Moscovitch, M., \& UmILT $\lambda$, C. (1991). Conscious and nonconscious aspects of memory: A neuropsychological framework of modules and central systems. In R. G. Lister \& H. J. Weingartner (Eds.), Perspectives on cognitive neuroscience (pp. 229-266). New York: Oxford University Press.

QuARTERmain, D. (1983). The role of catecholamines in memory processing. In J. A. Deutsch (Ed.), The physiological basis of memory (pp. 387-423). New York: Academic.

PACKARD, M. G., \& WHITE, N. M. (1990). Effect of posttraining injections of glucose on acquisition of two appetitive learning tasks. Psychobiology, 18, 282-286.

Rescorla, R. A., \& HeTH, D. C. (1975). Reinstatement of fear to an extinguished conditioned stimulus. Joumal of Experimental Psychology: Animal Behavior Processes, 1, 88-96.

Riccio, D. C., \& Ebner, D. L. (1981). Postacquisition modifications of memory. In N. E. Spear \& R. R. Miller (Eds.), Information processing in animals: Memory mechanisms (pp. 291-317). Hillsdale, NJ: Erlbaum.

Richardson, R., Riccio, D. C., \& Mowrey, H. (1982). Retrograde amnesia for previously acquired Pavlovian conditioning: UCS exposure as a reactivation treatment. Physiological Psychology, 10, 384-390.

Rodriguez, W. A., Phillips, M. Y., Rodriguez, S. B., * MartiNEZ, J. L., JR. (in press). Cocaine administration prior to reactivation facilitates later acquisition of an avoidance response in rats. Psychopharmacology.

SARA, S. J. (1985). Noradrenergic modulation of selective attention: Its role in memory retrieval. In D. Olton, E. Gamzu, \& S. Corkin (Eds.), Memory dysfunctions: An integration of animal and human research from clinical and pre-clinical perspectives. (Annals of the 
New York Academy of Sciences, Vol. 444, pp. 178-193). New York: New York Academy of Sciences.

SARA, S. J. (1991). Neuromodulatory influences on retrieval. In J. Weinman \& J. Hunter (Eds.), Memory: Neurochemical and abnormal perspectives (pp. 105-128). New York: Hardwood Academic.

Schulteis, G., \& Martinez, J. L., JR. (1992). Peripheral modulation of learning and memory: Enkephalins as a model system. Psychopharmacology. 109, 347-364.

Selden, N. R. W., Everitt, B. J., Jarrard, L. E., \& Robbins, T. W. (1991). Complementary roles for the amygdala and hippocampus in aversive conditioning to explicit and contextual cues. Neuroscience, 42, 335-350.

SPEAR, N. E. (1976). Retrieval of memories: A psychobiological approach. In W. K. Estes (Ed.), Handbook of learning and cognitive processes: Vol. 4. Attention and memory (pp. 17-90). Hillsdale, NJ: Erlbaum.

SPEAR, N. E. (1981). Extending the domain of memory retrieval. In N. E. Spear \& R. R. Miller (Eds.), Information processing in animals: Memory mechanisms (pp. 341-378). Hillsdale, NJ: Erlbaum.

Spear, N. E., Hamberg, J. M., \& Bryan, R. (1980). Forgetting of recently acquired or recently reactivated memories. Learning \& Motivation, 11, 456-475.

Spear, N. E., Miller, J. S., \& Jagielo, J. A. (1990). Animal memory and learning. Annual Review of Psychology, 41, 169-211.

Spear, N. E., \& Mueller, N. E. (1984). Consolidation as a function of retrieval. In H. Weingartner \& E. S. Parker (Eds.), Memory consolidation: Psychobiology of cognition (pp. 111-147). Hillsdale, NJ: Erlbaum.

SQuire, L. R., \& DAvis, H. P. (1981). The pharmacology of memory: A neurobiological perspective. Annual Review of Pharmacology \& Toxicology, 21, 323-356.

Stone, W. S., CotTrill, K. L., Walker, D. L., \& Gold, P. E. (1988). Blood glucose and brain function: Interactions with CNS cholinergic systems. Behavioral \& Neural Biology, 50, 325-334.

StONE, W. S., RudD, R. J., \& Gold, P. E. (1990). Amphetamine, epinephrine, and glucose enhancement of memory retrieval. Psychobiology, 18, 227-230.

Stone, W. S., Walser, B., Gold, S. D., \& Gold, P. E. (1991).
Scopolamine- and morphine-induced impairments of spontaneous alternation performance in mice: Reversal with glucose and with cholinergic and adrenergic agonists. Behavioral Neuroscience, 105, 264-271.

Teyler, T. J., \& DiScenna, P. (1986). The hippocampal memory indexing theory. Behavioral Neuroscience, 100, 147-154.

Tulving, E., \& ThOMpson, D. M. (1973). Encoding specificity and retrieval processes in episodic memory. Psychological Review, 80, 352-373.

WAGNER, A. R., \& BRANDON, S. E. (1989). Evolution of a structured connectionist model of Pavlovian conditioning (AESOP). In S. B. Klein \& R. R. Mowrer (Eds.), Contemporary leaming theories: Pavlovian conditioning and the status of traditional learning theory (pp. 149189). Hillsdale, NJ: Erlbaum.

WENK, G. L. (1989). An hypothesis on the role of glucose in the mechanism of action of cognitive enhancers. Psychopharmacology, 99, $431-438$.

White, N. M. (1991). Peripheral and central memory-enhancing actions of glucose. In R. C. A. Frederickson, J. L. McGaugh, \& D. L. Felten (Eds.), Peripheral signaling of the brain: Role in neural-immune interactions and learning and memory (pp. 421-441). Toronto: Hogrefe \& Huber.

White, N. M., \& MEssier, C. (1988). Effects of adrenal demedulation on the conditioned emotional response and on the memory improving action of glucose. Behavioral Neuroscience, 102, 499-503.

White, N. M., \& MiLner, P. M. (1992). The psychobiology of reinforcers. Annual Review of Psychology, 43, 443-471.

WiCKelgReN, W. A. (1976). Memory storage dynamics. In W. K. Estes (Ed.), Handbook of learning and cognitive processes: Vol. 4. Attention and memory (pp. 321-361). Hillsdale, NJ: Erlbaum.

Winocur, G., \& GiLBERT, M. (1984). The hippocampus, context, and information processing. Behavioral \& Neural Biology, 40, $27-43$.

Winocur, G., Rawlins, J. N. P., \& Gray, J. A. (1987). The hippocampus and conditioning to contextual cues. Behavioral Neuroscience, $101,617-625$.

(Manuscript received January 11, 1993; revision accepted for publication March 4, 1993.) 